\title{
Uterine conserving surgery in a case of cervicovaginal agenesis with cloacal malformation
}

\author{
Vineet Mishra $^{1 *}$, Suwa Ram Saini ${ }^{2}$, Priyankur Roy ${ }^{1}$, Rohina Aggarwal ${ }^{1}$, Ruchika Verneker ${ }^{1}$, \\ Shaheen Hokabaj ${ }^{1}$
}

${ }^{1}$ Department of Obstetrics and Gynecology, IKDRC, Ahmedabad, Gujarat, India
${ }^{2}$ Department of Obstetrics and Gynecology, S. P. Medical College, Bikaner, Rajasthan, India

Received: 30 December 2016

Accepted: 02 February 2017

\section{*Correspondence:}

Dr. Vineet Mishra,

E-mail: vineet.mishra.ikdrc@gmail.com

Copyright: () the author(s), publisher and licensee Medip Academy. This is an open-access article distributed under the terms of the Creative Commons Attribution Non-Commercial License, which permits unrestricted non-commercial use, distribution, and reproduction in any medium, provided the original work is properly cited.

\begin{abstract}
Cervico-vaginal agenesis (MRKHS) with normally formed uterus along with cloacal malformation is a very rare mullerian anomaly. We report a case, of a 13-year-old girl who was admitted at our tertiary care center with complaints of primary amenorrhea and cyclical lower abdominal pain for 3 months. Clinical examination and radiological investigations revealed complete cervico-vaginal agenesis with normal uterus with hematometra with horse shoe kidney. Vaginoplasty was done by McIndoe's method with uterovaginal anastomosis and neocervix formation. Malecot's catheter was inserted in uterine cavity. Vaginal mould was kept in the neovagina. Mould was removed after 10 days under anaesthesia and repeat hysteroscopy with insertion of a small piece of malecot's catheter was performed under hysteroscopic guidance into the uterine cavity through neocervix and lower end fixed to the vagina. After 3 months, the malecot's catheter was removed. During follow up, she was menstruating normally at 6 months post-operatively and had a completely healed vaginal mucosa. Earlier hysterectomy was considered as a definitive surgery for this condition; however, it has been replaced with more conservative approach, like uterovaginal anastomosis with creation of neovagina. In literature, successful pregnancy has been reported in these patients who underwent conservative surgery.
\end{abstract}

Keywords: Cervico-vaginal agenesis, Cloacal malformation, Mayer-Rokitansky-Kuster-Hauser Syndrome, McIndoe's vaginoplasty

\section{INTRODUCTION}

Cervico-vaginal agenesis is one of the most significant congenital anomaly of female reproductive tract from physical and psychological perspective. Vagina is a composite structure formed partly from the mullerian duct (upper two-third) and partly from urogenital sinus (lower one-third). The prevalence of congenital vaginal agenesis is 1 in $4000-5000$ live-births ${ }^{1}$, whereas prevalence of congenital cervical agenesis is 1 in 80,000100,000 live-births. ${ }^{1-3}$ Vaginal agenesis is most commonly associated with MRKH syndrome. ${ }^{4,5} \mathrm{MRKH}$ syndrome is described as congenital vaginal agenesis in an individual with normal female genotype, phenotype and normal endocrine status. These patients have rudimentary uterus or total absence of uterus but they have normal ovaries. Most of the patients with MRKH syndrome have small rudimentary uterus without any endometrial cavity but very rarely unilateral cornua with functioning endometrial cavity is present with opposite side being rudimentary. According to the American Fertility Society (AFS) classification of mullerian duct anomaly, vaginal agenesis should be classified as Type 1A mullerian anomaly \& cervical agenesis as Type 1B mullerian anomaly. Presence of functioning uterus with cervical agenesis is a big challenge for the gynecologist because a successful repair could restore normal menses and may preserve the patient's fertility. The most 
available successful surgical treatment to date for cervico-vaginal agenesis is neovagina creation followed by transabdominal approach to create an ostium between uterus and vagina through the dense fibrous tissue by application of stents.

\section{CASE REPORT}

A 13 year old girl was admitted at Institute of Kidney Diseases and Research Centre (IKDRC), Ahmedabad, with complaints of primary amenorrhea with cyclical lower abdominal pain for 3 months. She also had generalized weakness. On examination, her vitals were stable and her cardiovascular and respiratory system were normal. No otological anomalies were detected. She had normal secondary sexual characteristics with Tanner stage being 3 . There was a history of bilateral ectopic ureter with hypoplastic bladder with vulval anus diagnosed at birth. There was surgical history in childhood for cloacal malformation correction (anterior sagittal anorectoplasty) at the age of one and half month. Urinary bladder reconstruction and bilateral ectopic ureteric reimplantation was subsequently done at one and half year. Per-abdominal and vaginal examination revealed vaginal dimple without a normal vaginal orifice (Figure 1).

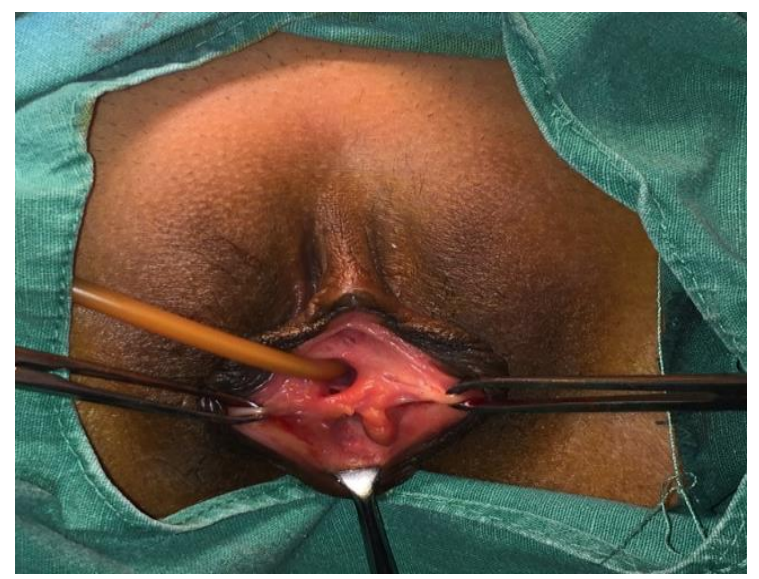

Figure 1: Pre-operative picture showing bilateral vaginal dimple.

On per-rectal examination uterus was felt high-up. Hematological investigations were within normal limits. USG abdomen and pelvis showed collection of approximately $7 \mathrm{cc}$ in the endometrial cavity (s/o hematometra). Both kidneys were joined, malrotated anteriorly, and situated in lumber region (s/o horse-shoe kidney) with bilateral mild hydronephrosis. MRI abdomen-pelvis revealed horse-shoe kidney with hematometra $(8 \mathrm{cc}$ ) with blind ended uterus with nonvisualization of cervix and vagina. Both fallopian tubes and ovaries were normal, and the ovaries were placed at the level of pelvic brim. Karyotyping was performed and it was normal (44XX).

\section{Operative technique}

Patient and her relatives were duly counseled regarding the surgical method and possible complications. She was admitted and was planned for neovagina creation by McIndoe's method and neocervix formation to connect the uterus and the proximal vagina. Partial thickness skin graft (STG) was taken from left thigh and graft sutured over mould with 3-0 catgut. Harvested area was dressed with glycerin gauze for 8 days.

Vaginal dimple was identified and dissection was done bilaterally on both sides of vaginal median raphe, then the raphe was cut and adequate vaginal space was created (Figure 2).

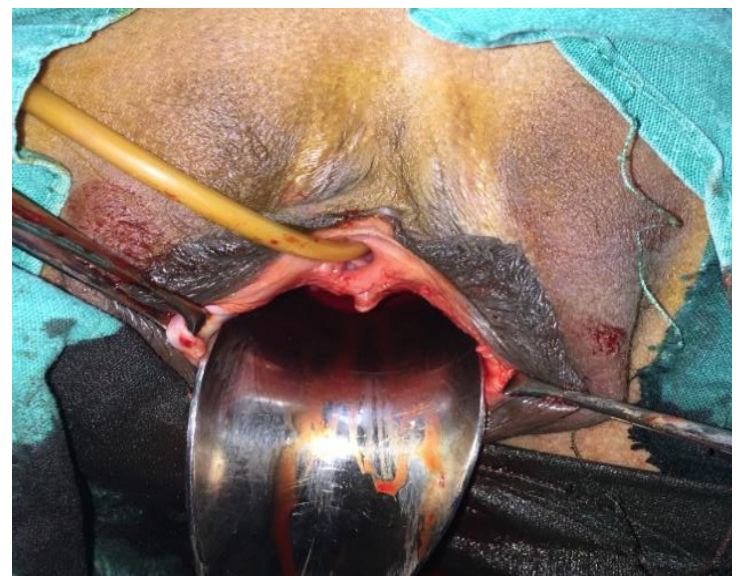

Figure 2: Intra-operative picture after creation of neovagina.

Laparotomy was performed and uterus with cervical agenesis was found per-operatively (Figure 3), bilateral ovaries with fallopian tubes were normal.

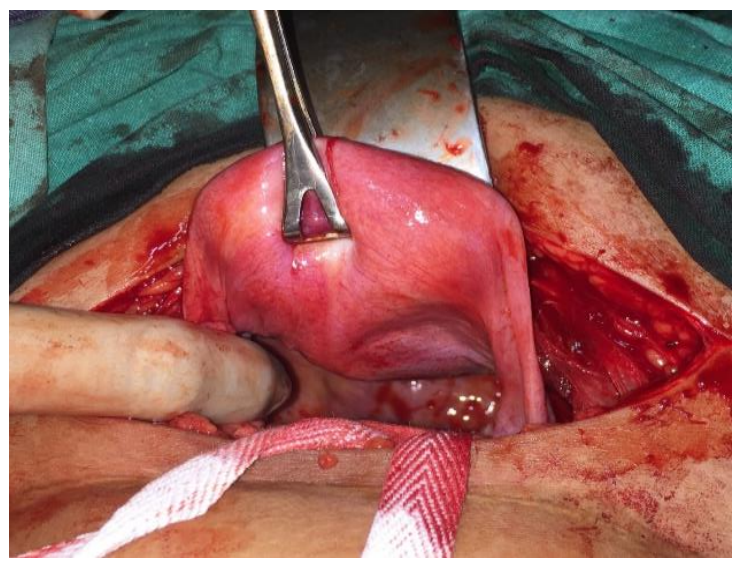

Figure 3: Intra-operative picture showing normal uterus with absent cervix and vagina.

A stab incision was given on the anterior wall of the uterus and hemorrhagic collection was drained. Hysteroscope was inserted through the stab incision and fixed on the lower edge of the uterus. A nick was given 
from below under the guidance of hysteroscopic light. Kocher's forceps were then inserted from above through the uterine incision and taken out from the most dependent conical part of lower part of the uterus.

Malecot's catheter and the mould on which skin graft was placed (Figure 4), was introduced into the neovagina by rail road method and the vulva was sutured such that the mould does not get expelled. The malecot's catheter was sutured to the posterior wall of the uterus by absorbable suture (Figure 5). Uterus was subsequently closed in 2 layers. The abdomen was closed in layers. She was kept nil per mouth post-operatively for 8 days. Parenteral antibiotics and nutrition was given.

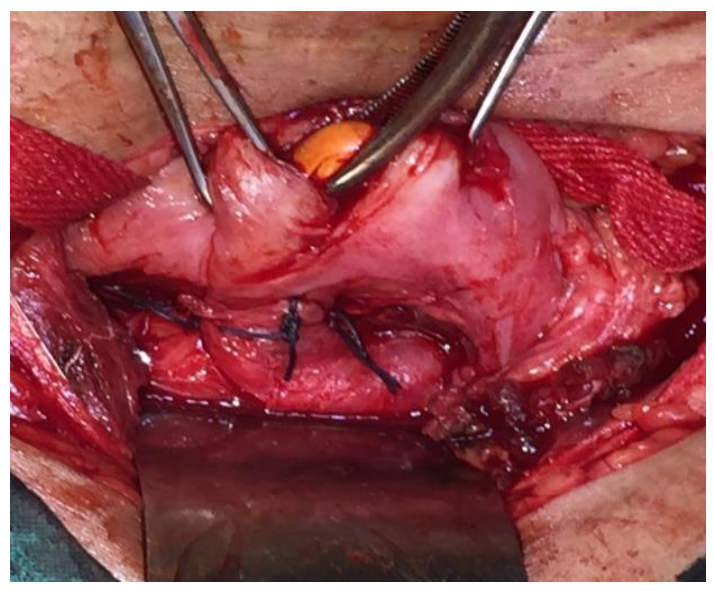

Figure 4: Intra-operative picture after utero-vaginal anastomosis (neocervix).

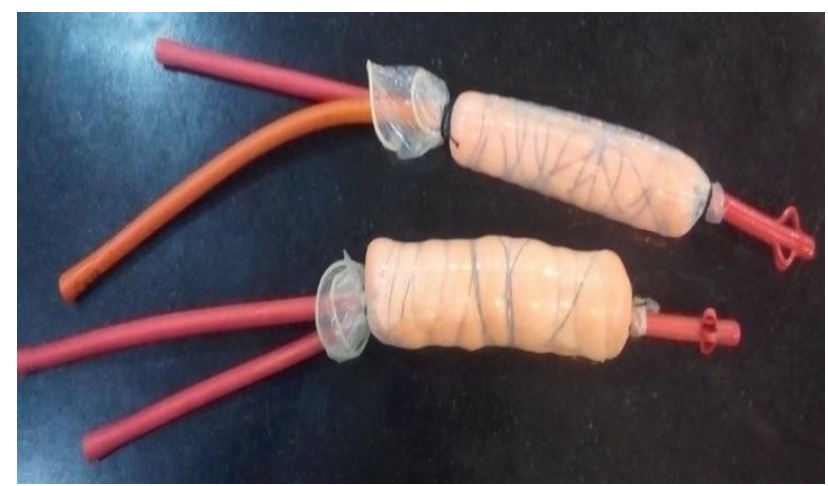

Figure 5: Vaginal mould used intra-operatively - split thickness skin graft (STG) is placed on this mould before inserting it into the neovagina.

On post-operative day 8 , she was retaken to the OT and the mould was removed under short GA. Vaginoscopy was also performed using $2.9 \mathrm{~mm}$ hysteroscope and the graft was found to be well taken up in all the patients. A small piece of malecot's catheter (stent) was introduced in the uterovaginal anastomosis and fixed to the lateral vaginal wall with non-absorbable suture so that the anastomosis remains patent. A new mould was kept in the neovagina (Figure 6). After removal of the foley's catheter on $8^{\text {th }}$ post-operative day, she voided normally.
She was discharged on post-operative day 14, with advice to change the mould twice daily, counselled about personal hygiene and intake of high protein diet.

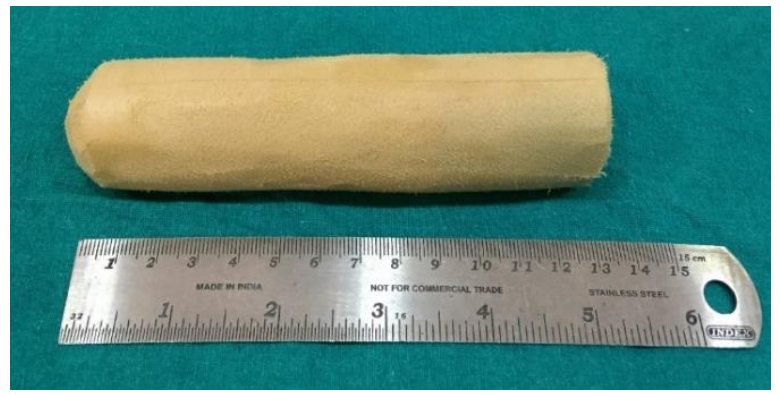

Figure 6: Vaginal mould used post-operatively-patient is discharged with this mould and advised to insert it into the vagina twice daily.

She is now on regular follow-up and have adequate vaginal space. The small piece of malecot's catheter (stent) which was left insitu, was removed under hysteroscopic guidance after 3 months. On follow-up at 6 months, she is menstruating normally and also has a completely healed vaginal mucosa (Figure 7). She is now advised to remove the mould only while urinating or defecating. Later, she needs to use the mould continuously at night till her marriage.

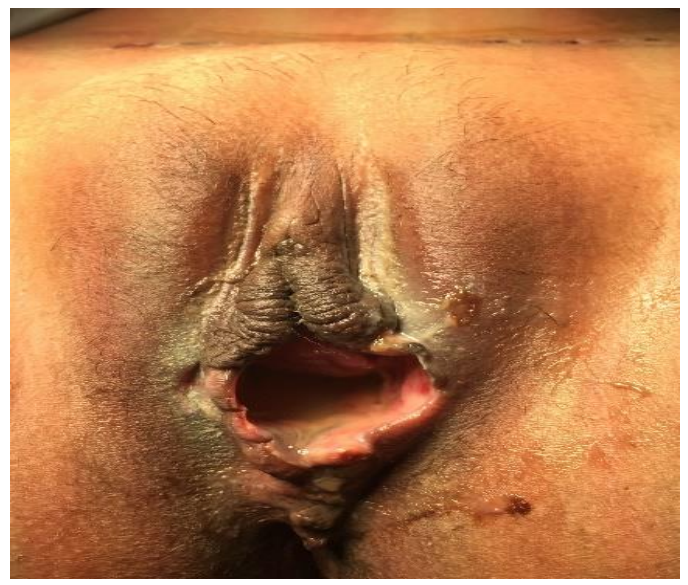

Figure 7: Follow-up picture of neovagina with the STG well taken up.

\section{DISCUSSION}

Mullerian agenesis can be partial or complete. Partial mullerian agenesis is more rarely encountered and is characterized by normal uterus and small vaginal pouch distal to the cervix. ${ }^{6,7}$ Complete mullerian agenesis (MRKH Syndrome) is the most common variant encountered and is characterized by congenital vaginal agenesis in an individual with normal female genotype, phenotype and normal endocrine status. These patients have a rudimentary development or total absence of uterus, but they have normal ovaries and the secondary sexual characteristics develop normally. MRKH may also 
be associated with anomalies of the renal system (34\%), skeletal system (12\%) and cervico-thoracic somite dysplasia (MURCS). Renal anomalies may include unilateral agenesis of kidney, ectopic kidney, horse-shoe kidney and skeletal anomalies may include fused vertebrae or other variants. Abnormal development in one of the urinary or the reproductive system is a strong evidence to search for congenital fusion defects of the cervical spine. ${ }^{8}$

Diagnosis is usually done by typical history of primary amenorrhea with cyclic lower abdominal pain. Transabdominal or trans-perineal ultrasonography may specify the level of obstacle and agenesis but is not very reliable for the diagnosis. Currently, MRI scanning appears to be the most reliable examination for the diagnosis of MRKH and other associated malformations. IVP and karyotyping may also be required for zeroing on the diagnosis.

Previously the recommended treatment of cervicovaginal agenesis was hysterectomy because complications of neocervico-vaginal formation were common. Recent advances in reproductive technology and minimal invasive surgical techniques means that conservative surgery is possible and should be considered as the first line treatment option. ${ }^{9}$ The surgical management of vaginal agenesis constitutes a significant reconstructive challenge for gynaecologists, the outcome of which affects both the physical and psychological health of the patient. Non-surgical creation of vagina by progressive dilatation of the pseudohymen membrane (Frank Technique) is the appropriate first line approach in the majority of patients. However, its success is unpredictable. The patient needs to be highly motivated and willing to continue long term dilatation. However, awkward positioning and tediousness, possibility of vaginal prolapse, stenosis and eversion are the major drawbacks of this method. ${ }^{10,11}$

There are various methods for surgically constructing neovagina. The difference among the various surgical approaches lies in the tissue used to line the neovagina. Many authors have used amnion as graft in vaginoplasty and reported excellent results. Amnion can be chosen as graft, because it is readily available, cheap, no pain at skin graft site, provides a protective cover over wound because of production of bactericidal enzymes and also has no problems of immune rejection since amnion does not express histocompatibility antigen. ${ }^{12,13}$

In this patient, we performed McIndoe's vaginoplasty along with an abdominal approach to drain the hematometra and create an uterovaginal anastomosis, and thus, forming the neocervix. After successful surgery we used the vaginal mould continuously to prevent restenosis. A small piece of malecot's catheter was fixed between the uterus and vagina that maintained patent drainage tract. After prolonged time, a fibrous tissue canal forms which epithelizes and works as neocervical canal. The patient's morbidity was decreased, symptoms were relieved, menstrual function was retained and functional vagina was formed. ${ }^{14}$

Preservation of the uterus should always be attempted in patients with cervico-vaginal agenesis with hematometra. Thus, reproductive capacity is preserved and patient should be aware of the fact that the possibility of conception exists and assisted reproductive techniques may be helpful. Few cases of successful outcome of pregnancy are reported in literature. Repeated episodes of hematometra, endometriosis and recurrent obstruction may ultimately require radical treatment, hysterectomy as the last option. ${ }^{15}$

\section{CONCLUSION}

Cervicovaginal agenesis in presence of uterus with functioning endometrium is a rare condition. Preservation of the uterus by uterovaginal anastomosis should always be attempted in such patients, as regular menstrual cycle makes a woman feel complete psychologically and removes the social stigma. Pregnancy has also been reported in few women after uterovaginal anastomosis. Though, hysterectomy should be considered as the ultimate mode of management after failure of uterovaginal anastomotic surgery.

\section{Funding: No funding sources \\ Conflict of interest: None declared \\ Ethical approval: Not required}

\section{REFERENCES}

1. Buttram VC. Mullerian anomalies and their management. Fertil Steril. 1983;40:159-63.

2. Rock JA, Carpenter SE, Wheeless CR, Jones HWJ. The clinical management of maldevelopment of uterine cervix. J Pelv Surg. 1995;1:129-33.

3. Creighton SM, Daves MC, Cutner A. Laparoscopic management of cervical agenesis. Fertil Steril. 2006;85:1510-13.

4. Saraf S, Saraf P. McIndoe's vaginoplasty: Revisited. Int J Gynaecol Obstet. 2007;6.

5. Gupta NP, Ansari MS. Mayer-Rokitansky-KusterHauser (MRKH) syndrome: A review. Ind $\mathrm{J}$ of Urology. 2007;18:111-6.

6. Jones HW, Scott WM. Hermaphroditism, genital anomalies and Related Endocrine disorders. 1958;2:327.

7. Jones HW, Wheeless CR. Salvage of the reproductive potential of women with anomalous development of the mullerian ducts. AJOG. 1969; 104:348-52.

8. Lyons JK. MURCS association: mullerian duct, renal and cervical vertebral defects. In: Smith's Recognizable Patterns of Human Malformation. 5th edition. Philadelphia, Pa: WB Saunders;1997:666.

9. Deffanges JV, Haddad B, Muset R, Paniel BJ. Uterovaginal anastomosis in women with uterine cervix atresia: Long term follow up and reproductive 
performance - A study of 18 cases. Hum Reprod. 2001;16:1722-5.

10. ACOG Committee Opinion. Non-surgical diagnosis and management of vaginal agenesis. Int J Gynaecol Obstet. 2002;79:167-70.

11. Frank RT. The formation of an artificial vagina without operation. Obstet Gynecol. 1938;35:1053-5.

12. McIndoe AH, Bannister JB. An operation for the cure of congenital absence of the vagina. J Obstet Gynaecol Br Emp. 1938;45(3):490-4.

13. McIndoe $\mathrm{AH}$. The treatment of congenital absence and obliterative conditions of vagina. Br J Plast Surg. 1950;2(4):254-67.
14. Roszaman, R, Ghazali, I. Vaginal and cervical agenesis - Hysterectomy in a young girl. Int Med J. 2006;5.

15. Raziel A, Friedler S, Gidoni Y, Ben A, Strassburger D. Surrogate in vitro fertilization outcome in typical and atypical form of Mayer-Rokitansky-KusterHauser syndrome. Hum Reprod. 2012;27(1):126-30.

Cite this article as: Mishra V, Saini SR, Roy P, Aggarwal R, Verneker R, Hokabaj S. Uterine conserving surgery in a case of cervicovaginal agenesis with cloacal malformation. Int J Reprod Contracept Obstet Gynecol 2017;6:1144-8. 